\title{
Cytoprotective Effects of Ethanolic Extract of Vernonium amygdalina Leaves on Alloxan Induced Hepato-Toxicity in Albino Wistar Rats
}

\author{
Peter A. I. ${ }^{1}$, Azu O. O. ${ }^{2}$, Edagha I. A. ${ }^{1}$ \\ ${ }^{1}$ Department of Anatomy, University of Uyo, Uyo, Nigeria \\ ${ }^{2}$ Department of Anatomy, University of Kwa-Zulu Natal, Durban, South Africa
}

Email address:

aniekanpeter@uniuyo.edu.ng (Peter A. I.)

\section{To cite this article:}

Peter A. I., Azu O. O., Edagha I. A. Cytoprotective Effects of Ethanolic Extract of Vernonium amygdalina Leaves on Alloxan Induced Hepato-Toxicity in Albino Wistar Rats. American Journal of Life Sciences. Vol. 3, No. 6, 2015, pp. 395-401.

doi: 10.11648/j.ajls.20150306.13

\begin{abstract}
This study was designed to investigate the cytoprotective effects of ethanolic extract of Vernonium amygadlina leaves on Alloxan induced hepato-toxicity in albino Wistar rats. A total of forty (45) male Wister Albino rats weighing between 130g to 200g were obtained from the animal house of the Faculty of Basic Medical Sciences, University of Calabar. The animals were randomly divided into nine groups of five rats each after acclimatization in the animal house of the College of Health Sciences, University of Uyo for two weeks. Group A served as control and were administered $1 \mathrm{ml}$ of distil water, Group B and C were administered with $150 \mathrm{mg} / \mathrm{kg}$ and $300 \mathrm{mg} / \mathrm{kg}$ of Vernonia amygdalina respectively. Group D was administered with $65 \mathrm{mg} / \mathrm{kg}$ of Alloxan. Group E and F were injected intraperitonially with $65 \mathrm{mg} / \mathrm{kg}$ of Alloxan and left for two weeks to become diabetic followed by administration with $150 \mathrm{mg} / \mathrm{kg}$ and $300 \mathrm{mg} / \mathrm{kg}$ of Vernonia amygdalina respectively. Group $\mathrm{G}$ and $\mathrm{H}$ were administered with $150 \mathrm{mg} / \mathrm{kg}$ and $300 \mathrm{mg} / \mathrm{kg}$ of Vernonia amygdalina respectively for two weeks, before they were injected intraperitonially with $65 \mathrm{mg} / \mathrm{kg}$ of Alloxan followed by continuation of $150 \mathrm{mg} / \mathrm{kg}$ and $300 \mathrm{mg} / \mathrm{kg}$ of Vernonia amygdalina for another two weeks. Group I was administered with $65 \mathrm{mg} / \mathrm{kg}$ of Alloxan and insulin lente (1.0 IU) daily for four weeks. The animals were sacrificed on the $29^{\text {th }}$ day, using chloroform inhalation method and their liver harvested, processed and stained using Haematoxylin and Eosin method. Stained slides were viewed using light microscope. Result showed normal architecture of the liver, hepatocytes (H), central vein (CV), sinusoid (S) and nucleus in the control group. The cellular architecture of the Alloxan groups D, E, F. G, H and I were all distorted with cytoplasmic vacuolation, sinusoidal spaces dilation and nuclear degeneration. These distortions were severe in the Alloxan only group D. The groups that were administered with VA were able to ameliorate this changes; the groups that were administered with VA two weeks before the administration of the Alloxan (G, H.) had lesser cellular changes than the groups that were administered with Alloxan two weeks before VA administration, (E, F.). The groups that were administered with VA only (B, C.) had a near normal hepatic architecture. VA has cytoprotective potentials that can be used to prevent hepatic damage in diabetic patients.
\end{abstract}

Keywords: Vernonium amygadlina, Alloxan, Hepato-Toxicity, Cytoprotective

\section{Introduction}

The use of plants for healing purposes predates human history and forms the origin of modern medicine [1]. Focus on plant research has increased in recent times all over the world and results have shown an immense potential of some plants in various tradition [2]. Antidiabetic medicinal plants are known to exert their beneficial effects on diabetes via various modes and mechanisms depending on the phytochemical and bioactive agents endowed in such plants or collection of plants [3]. These mechanisms have been enumerated to include; modulation of carbohydrate and lipid metabolism in the liver, influence on beta cell integrity and insulin releasing activity [4]. The use of plant derived natural compounds as parts of herbal preparation for alternate source of medicament continues to play major roles in chemotherapy especially in third world countries [5]. Several studies carried out have shown that traditional medicines could provide better glycaemic control than currently used 
conventional drugs [6]. Plants by means of secondary metabolism contain a variety of herbal and non-herbal and ingredients that can ameliorate disease condition by acting on a variety of targets in the host organism. On the basis of the above, polyherbal therapy is considered therapeutic approach to management of diabetes given its multifactorial pathogenicity [7].

Vernonia amygdalina is a small shrub that grows in the tropical Africa [8] and is commonly called bitter leaf because of its bitter taste [9] The leaves may be consumed either as a vegetable or its aqueous extracts as tonic for the treatment of various illnesses [3, 10]. Many herbalists and naturopathnic doctors recommend aqueous extract for their patients as treatment for emesis, nausea, diabetes, loss of appetite, dysentery and other gastrointestinal problems. It may help suppress, delay or kill cancerous cells in many ways such as induction of apoptosis as determined in cell culture and animal studies [11]. Diabetes is one of the oldest known diseases [12]. The great Indian physician Sushruta identified the disease and classified it as medhumeda [13]. He further identified it with obesity, advising exercises to help cure it. The first complete clinical description of diabetes was given by the Ancient Greek physician Aretaeus of Cappadocia, who noted the excessive amount of urine which passed through the kidneys and gave the disease the name "Diabetes" [12]. VA had been reported to lower blood glucose in earlier study [14]. An association between type 2 diabetes mellitus and non-alcoholic fatty liver disease, which describes a wide spectrum of liver disorders from steatosis to cirrhosis, has long been recognized [15-16]. The objective of this work therefore was to investigate the cytoprotective effects of Ethanolic Extract of Vernonium amygdalina leaves on Alloxan Induced hepato-toxicity in Albino Wister rats.

\section{Material and Methods}

\subsection{Plant Collection and Authentication}

Fresh leaves of Vernonia amygdalina were collected from Uyo local government area, Akwa Ibom state, Nigeria. It was identified and authenticated by a taxonomist, in the Department of Botany, University of Uyo, Akwa Ibom, Nigeria with reference no UUH 2083. Ethical approval was given by the Faculty of Basic Medical sciences, University of Uyo. The leaves of Vernomia amygdalina were plucked from its stem, weighed and sliced. The sliced leaves were grinded with a manual grinder, after which $99 \%$ of ethanol was added to the leave and continuous stirring of the mixtures was done. The mixture was allowed to stay for two days with frequently stirring. A clean transparent cloth was used to filter the mixtures. After filtration, the solvent was removed under reduced pressure using a rotary evaporator at temperature below $50^{\circ} \mathrm{C}$ and stored in a refrigerator until required for use.

\subsection{Experimental Animals}

A total of forty (45) male Wister Albino rats weighing between $130 \mathrm{~g}$ to $200 \mathrm{~g}$ were obtained from the animal house of the Faculty of Basic Medical Sciences, University of Calabar. Following acclimatization period of two weeks, the rats were individually identified by colour tattoo and weighed. The rats were kept in plastic cage at room temperature with twelve hours ligh/dark cycle. They had access to their feed and a hygienic environment maintained to prevent infection. The animals were randomly divided into nine groups of five rats each. Group A serves as control and were administered $1 \mathrm{ml}$ of distil water, Group B and C were administered with $150 \mathrm{mg} / \mathrm{kg}$ and $300 \mathrm{mg} / \mathrm{kg}$ of Vernonia amygdalina respectively. Group D was administered with $65 \mathrm{mg} / \mathrm{kg}$ of Alloxan. Group E and F were injected intraperitonially with $65 \mathrm{mg} / \mathrm{kg}$ of Alloxan and left for two weeks to become diabetic followed by administration with $150 \mathrm{mg} / \mathrm{kg}$ and $300 \mathrm{mg} / \mathrm{kg}$ of Vernonia amygdalina respectively. Group $\mathrm{G}$ and $\mathrm{H}$ were administered with $150 \mathrm{mg} / \mathrm{kg}$ and $300 \mathrm{mg} / \mathrm{kg}$ of Vernonia amygdalina respectively for two weeks, before they were injected intraperitonially with $65 \mathrm{mg} / \mathrm{kg}$ of Alloxan followed by continuation of $150 \mathrm{mg} / \mathrm{kg}$ and $300 \mathrm{mg} / \mathrm{kg}$ of Vernonia amygdalina for another two weeks. Group I was administered with $65 \mathrm{mg} / \mathrm{kg}$ of Alloxan and insulin lente (1.0 IU) daily for four weeks. The animals were sacrificed on the $29^{\text {th }}$ day, using chloroform inhalation method and their liver harvested, processed and stained using the Haematoxylin and Eosin method. Stained slides were viewed using light microscope.

\section{Results}

Group A: Photomicrograph of the histology of the liver administered with distil water. Showing normal liver architecture; the central vein $(\mathrm{V})$, hepatocytes plates $(\mathrm{H})$, sinusoidal spaces $(\mathrm{S})$ and nuclei $(\mathrm{N})$ are all normal $\mathrm{H} \& \mathrm{E}, \times$ 100 and $X 400$ as shown in Fig. 1.

Group B: Photomicrograph of the histology of the liver administered with Photomicrograph of group B Administered with V.A only $(150 \mathrm{mg} / \mathrm{kg})$. Showing normal liver architecture; the central vein $(\mathrm{V})$, hepatocytes plates $(\mathrm{H})$, sinusoidal spaces $(\mathrm{S})$ and nuclei $(\mathrm{N})$ are all normal $\mathrm{H} \& \mathrm{E}, \times$ 100 and $X 400$ as shown in Fig 2.

Group C: Photomicrograph of the histology of the liver administered with V.A only $(300 \mathrm{mg} / \mathrm{kg})$; showing normal liver architecture; the central vein $(\mathrm{V})$, hepatocytes plates $(\mathrm{H})$, sinusoidal spaces $(\mathrm{S})$ and nuclei $(\mathrm{N})$ are all normal $\mathrm{H} \&$ $\mathrm{E}, \times 100$ and $\mathrm{X} 400$ as shown in Fig 3 .

Group D: Photomicrograph of the histology of the liver administered administered with $65 \mathrm{mg} / \mathrm{kg}$ of alloxan showing cellular cytoplasmic vacuolation (V), sinusoidal space dilatation (S) and nuclei pyknotic changes $\mathrm{H} \& \mathrm{E}, \times 100$ and $\mathrm{X} 400$ as shown in Fig 4.

Group E: Photomicrograph of the histology of the liver Administered with Alloxan 2 weeks before Administration of $(150 \mathrm{mg} / \mathrm{kg})$ of VA shows cellular swelling, sinusoidal dilatation, nuclear degeneration (ND) and clumping $\mathrm{H} \& \mathrm{E}, \times$ 100 and $X 400$ as shown in Fig 5.

Group F: Photomicrograph of the histology of the liver Administered with alloxan 2 weeks before administration of VA (300mg) shows cellular proliferation, cytoplasmic 
vacuolation, slight area nuclear degeneration and inflammatory cell H \& E, $\times 100$ and X 400 as shown in Fig 6.

Group G: Photomicrograph of the histology of the liver Administered with $(150 \mathrm{mg} / \mathrm{kg})$ of V.A for 2 weeks before $65 \mathrm{mg} / \mathrm{kg}$ of Alloxan is administered and VA continued after Aloxan administration, shows cellular proliferation (Cp), and slight area of vacuolation $\mathrm{V}$ and dilatation of the sinusoids $\mathrm{H}$ $\& \mathrm{E}, \times 100$ and $\mathrm{X} 400$ as shown in Fig 7.

Group H: Photomicrograph of the histology of the liver Administered with $(300 \mathrm{mg} / \mathrm{kg})$ of V.A for 2 weeks before
$65 \mathrm{mg} / \mathrm{kg}$ of Alloxan is administered and VA continues after aloxan administration showing only slight areas of sinusoidal dilatation and mild nuclei pyknotic changes. $\mathrm{H} \& \mathrm{E}, \times 100$ and X 400 as shown in Fig 8.

Group I: Photomicrograph of the histology of the liver Administered with $65 \mathrm{mg} / \mathrm{kg}$ of Alloxan with 1 iu of insulin daily for 4 weeks shows normal liver architecture; the central vein $(\mathrm{V})$, hepatocytes plates $(\mathrm{H})$, sinusoidal spaces $(\mathrm{S})$ are slightly dilated and nuclei $(\mathrm{N})$ are normal $\mathrm{H} \& \mathrm{E}, \times 100$ and $\mathrm{X} 400$ as shown in Fig. 9.
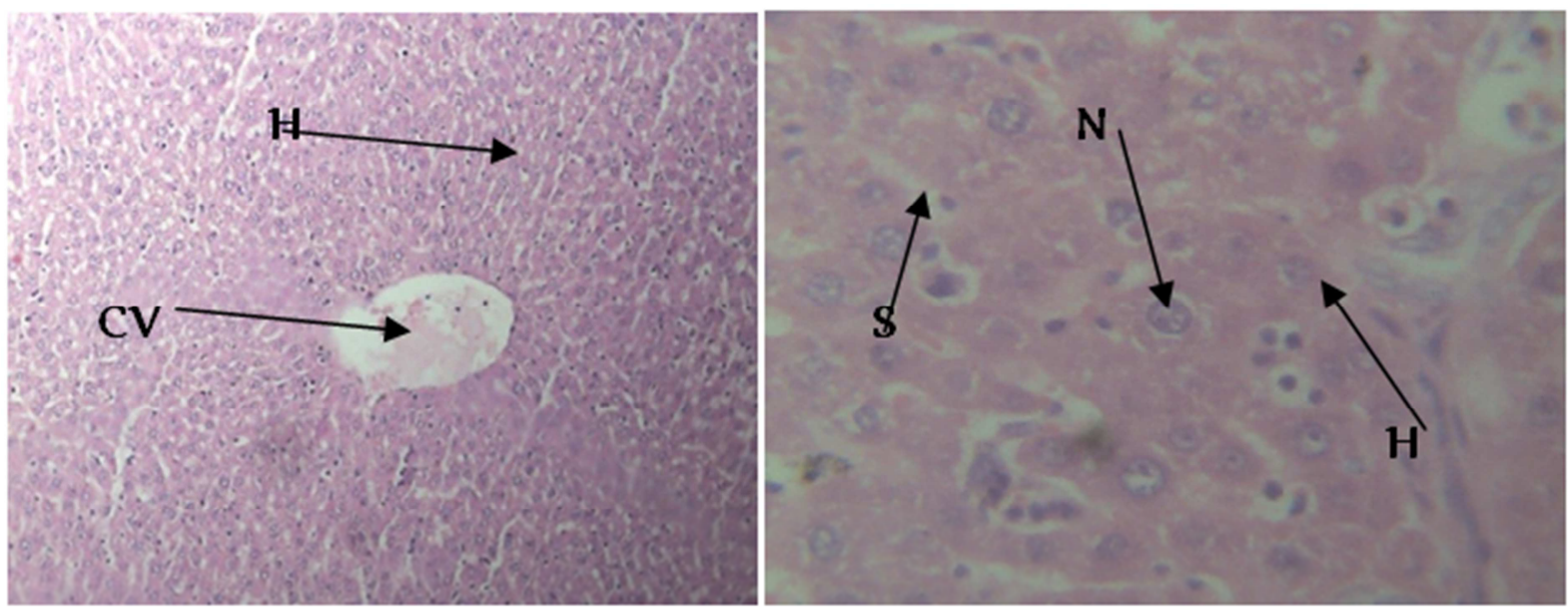

Fig. 1. Photomicrograph of control group A administered with normal saline shows normal architecture of the liver, hepatocytes (H), central vein (CV), sinusoid (S) and nucleus (N).
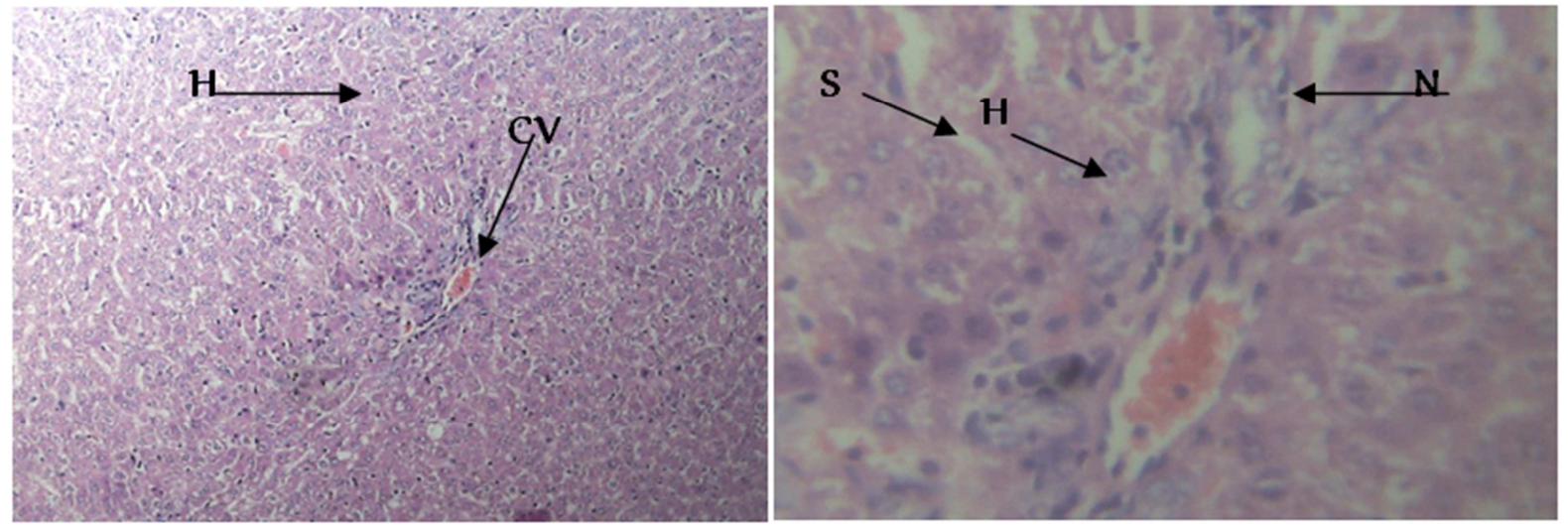

Fig. 2. Photomicrograph of group B Administered with V.A only (150mg/kg).
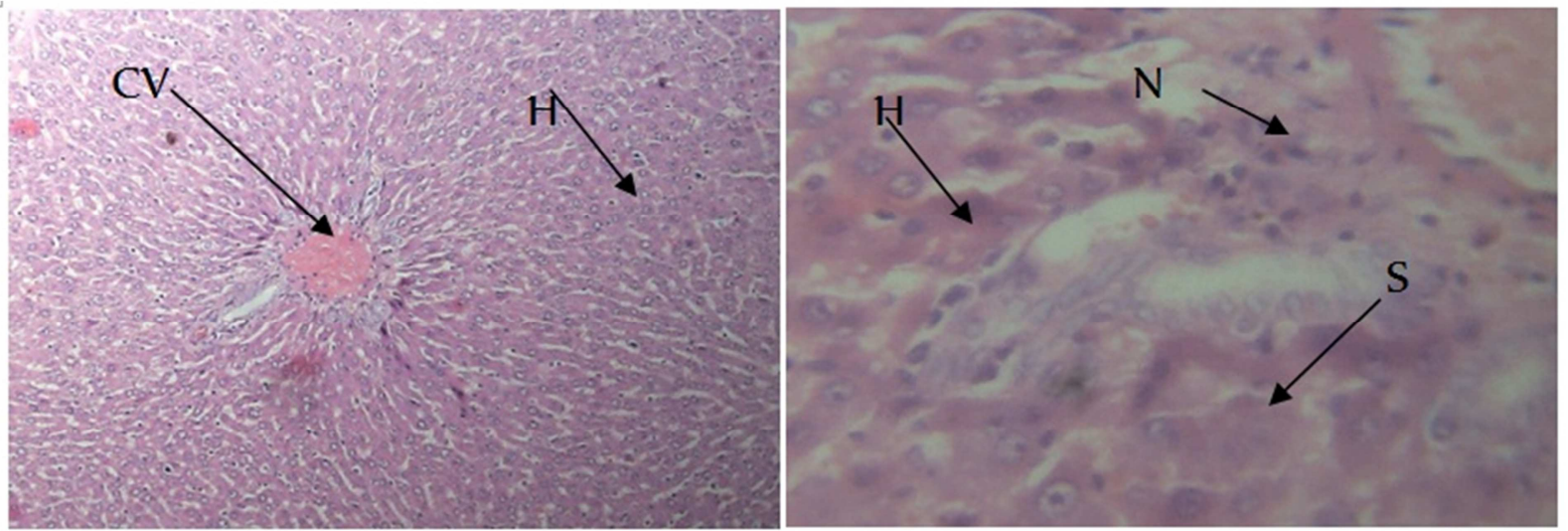

Fig. 3. Photomicrograph of group C Administered with V.A only (300mg/kg). 


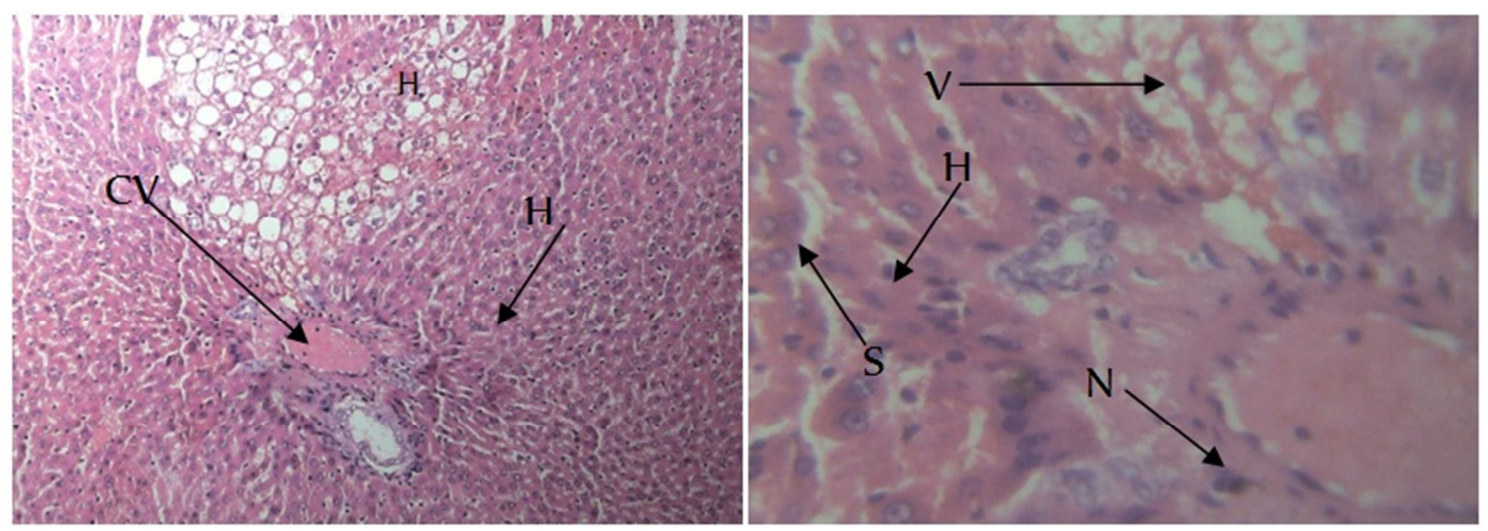

Fig. 4. Photomicrograph of group D administered with $65 \mathrm{mg} / \mathrm{kg}$ of alloxan.
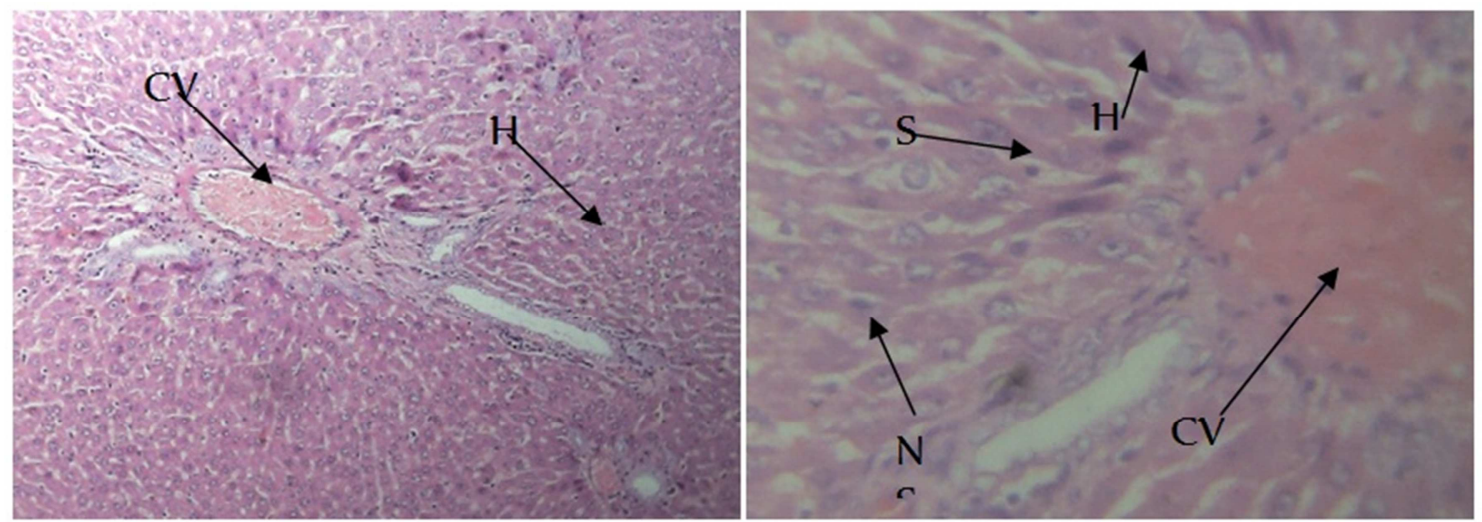

Fig. 5. Photomicrograph of group E Administered with Alloxan 2 weeks before Administration of $(150 \mathrm{mg} / \mathrm{kg})$ of VA.
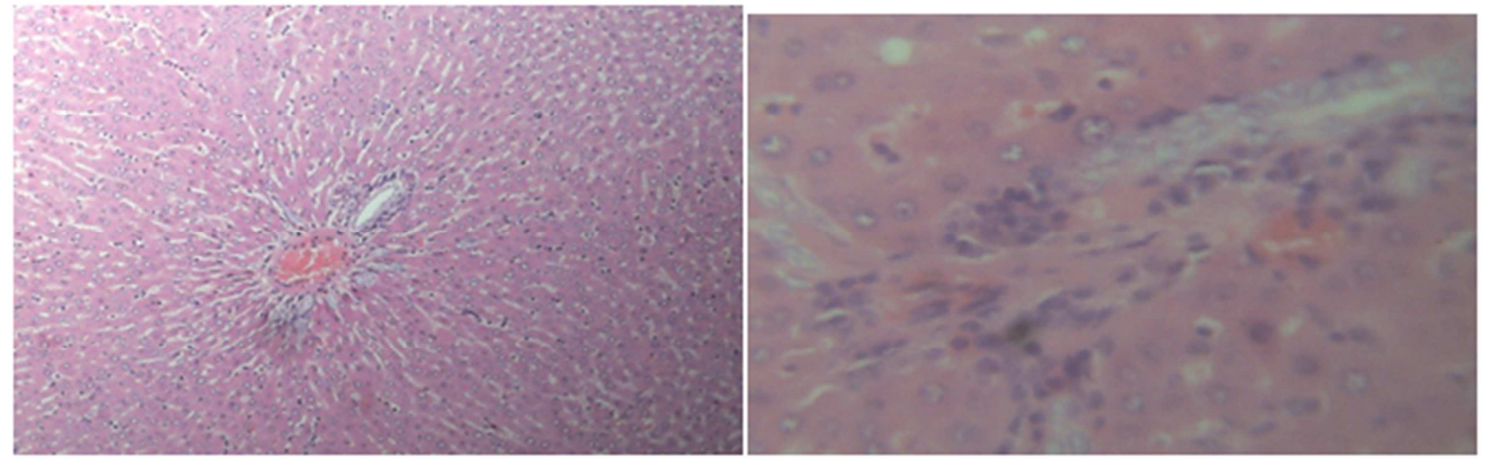

Fig. 6. Photomicrograph of Group F administered with alloxan 2 weeks before administration of VA (300mg).
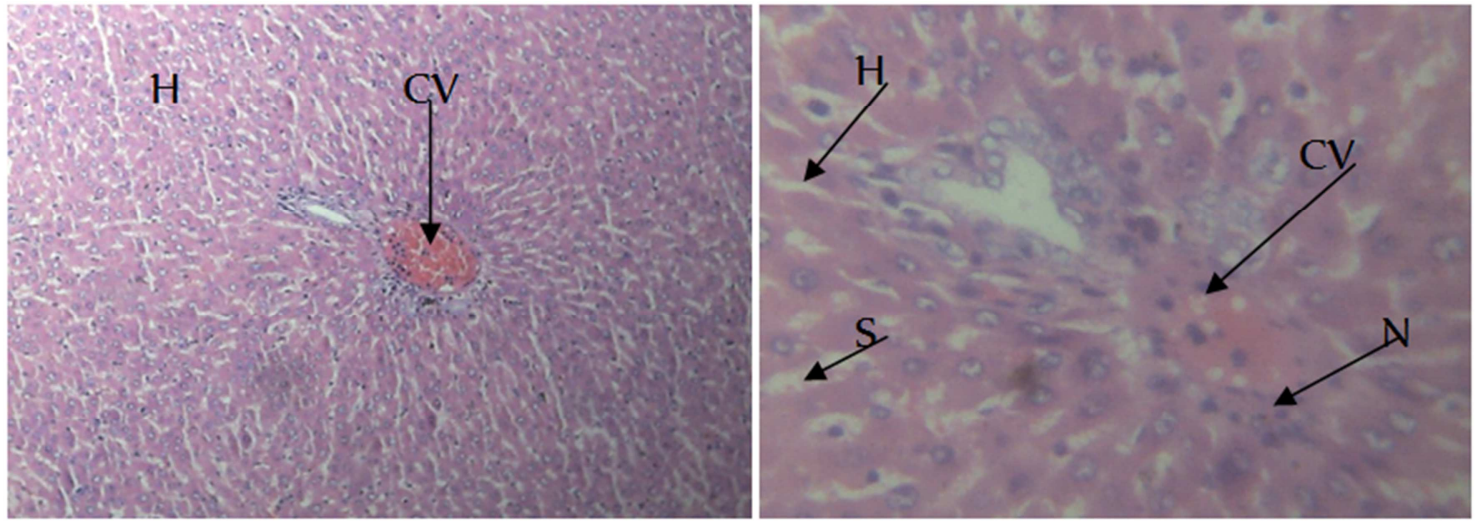

Fig. 7. Photomicrograph of group G Administered with (150mg/kg) of V.A for 2 weeks before $65 \mathrm{mg} / \mathrm{kg}$ of Alloxan is administered and VA continued after Aloxan administration. 

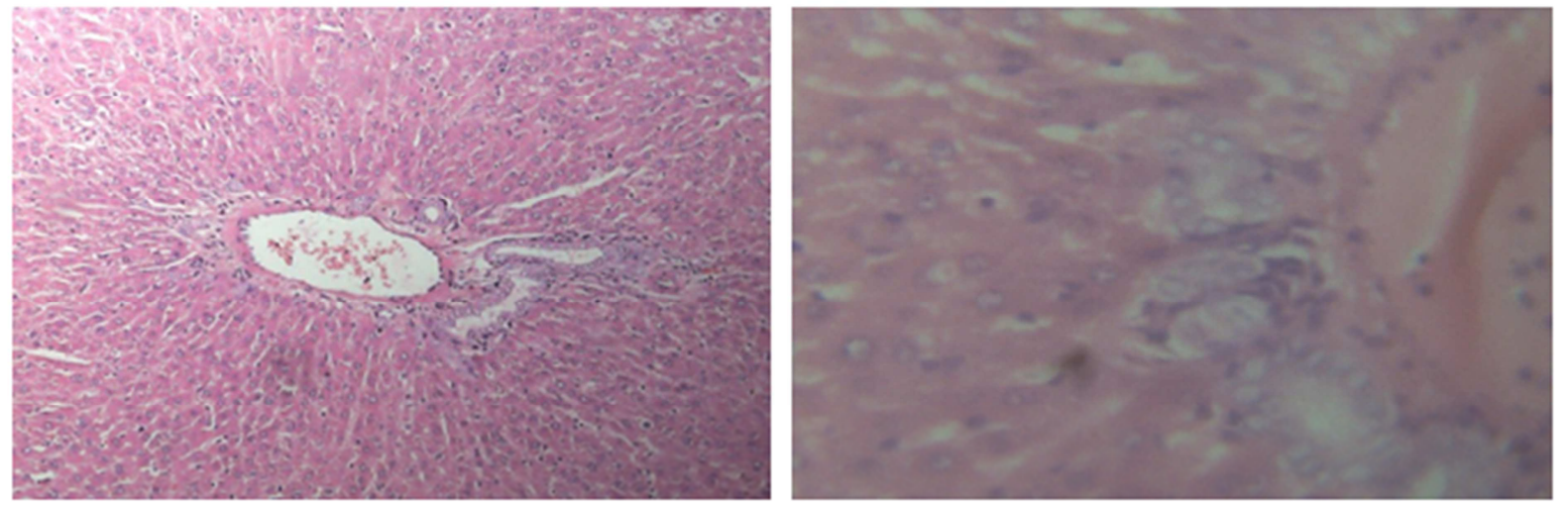

Fig. 8. Photomicrograph of group H Administered with (300 mg/kg) of V.A for 2 weeks before $65 \mathrm{mg} / \mathrm{kg}$ of Alloxan is administered and VA continues after aloxan administration.
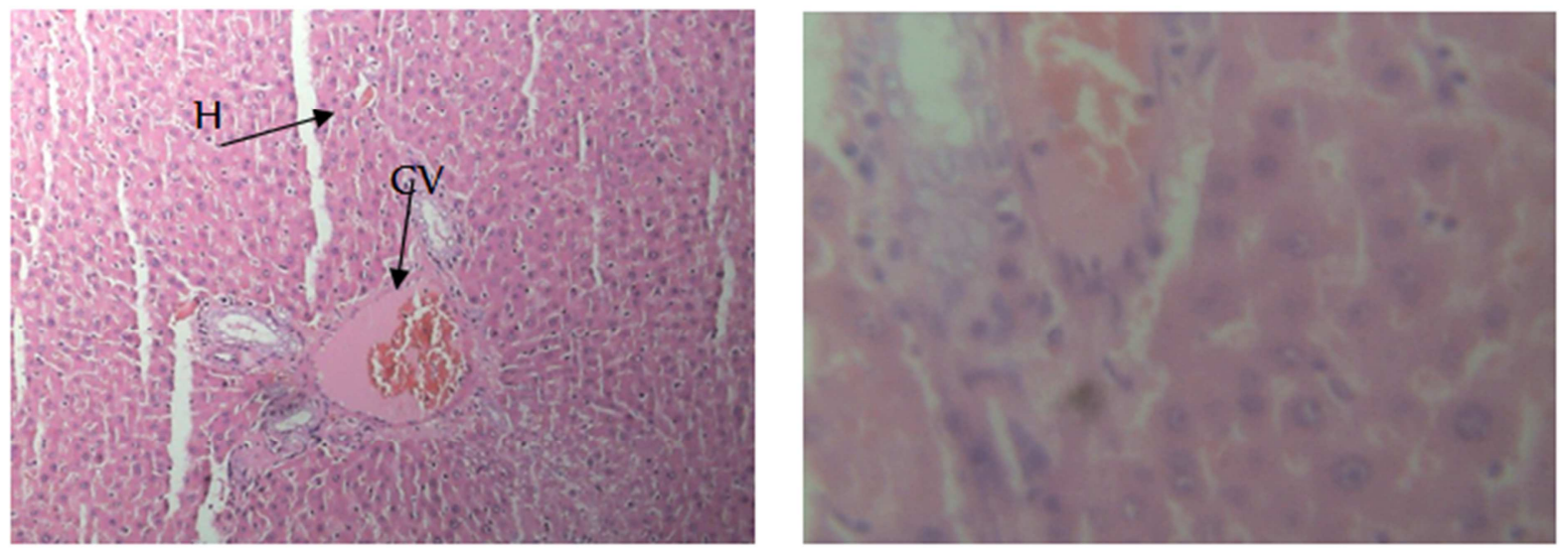

Fig. 9. Photomicrograph of I administered with $65 \mathrm{mg} / \mathrm{kg}$ of Alloxan with 1 iu of insulin daily for 4 weeks.

\section{Discussion}

Animal models of type 1 diabetes mellitus (T1DM) using chemical induction by Alloxan (ALX) could provide valuable information about the natural history of nonalcoholic fatty liver and improve our understanding of the mechanisms responsible for this condition [17]. However, few long-term studies of liver injury were well documented [18 - 20].

This study has shown that ALX is harmful to the histology of the liver as shown by the distortion of the liver architecture in group D. ALX is one of the frequently used beta-cytotoxic agents for the induction of Type-1 diabetes mellitus in animal models [21]. Alloxan was used in this study to induce the liver damage; causing cellular proliferation, cytoplasmic vacuolation, sinusoidal spaces dilation and nuclear degeneration. This collaborated with the findings of a study which demonstrated that rats with type 1 diabetes Mellitus induced by intravenous ALX; presented with biochemical changes in blood and morphological and ultrastructural lesions in the liver that largely resembled chronic liver disease in humans[17]. Liver changes ranged from the fatty degeneration of liver cells to steatohepatitis and peri-portal fibrosis. Clinical and experimental evidence suggests that diabetes mellitus (DM) affects the liver in addition to blood vessels, kidneys, retina and nerves [22 - 25].
The findings of our study also elucidated the protective effect of Vernonia amygdalina leaf extract on the liver during diabetes mellitus disease management. The leaves of VA had earlier been shown to lower blood sugar levels [26]. This sugar lowering effect must have been the reason for the improvement in cellular architecture in groups treated with VA. This is important because the liver plays a pivotal role in detoxification of xenobiotics and drugs in biological systems. Hepatic damage has been reported to upset the normal metabolic activities in the body [27]. The groups that were administered with VA were able to ameliorate this changes; the groups that were administered with VA two weeks before the administration of the ALX had lesser cellular changes than the groups that were administered with ALX two weeks before VA administration. This may be a result of better glycaemic control in these groups as VA has been shown to lower blood sugar. Above all there are numerous plants and traditional formulations available for the treatment of liver diseases [28, 29]. VA is one plant with great potential in our country.

The groups that were administered with various doses of VA did not have any detrimental effect as shown by normal liver architecture, central vein, hepatocytes plates, sinusoidal spaces and nuclei this corroborated with recent findings that VA had no detrimental effects at various doses in experimental rats. $[30,31]$ 
The insulin and Alloxan group had normal cellular architecture when compared with the control. Insulin is a known hypoglycemic agent [32]. Supporting our argument; that VA worked through the same mechanism of lowering blood sugar to prevent hepatic damage.

In conclusion, diabetes induced by Alloxan is capable of inducing liver damage in Wistar rats with distorted hepatic architecture, cytoplasmic vacuolation, sinusoidal spaces dilation and nuclear degeneration. Vernonia amygdalina is capable of ameliorating these changes through mechanisms yet to be elucidated. Therefore Vernonia amygdalina or its active components should be incorporated into diabetic management.

\section{References}

[1] Ajibade A. J., Fakunle P. B., Ashamu E. A. and Owolabi S. O. Some morphological changes on the kidney of adult Wistar rats following administration of crude extract of Ocimum gratissimum Journal of Medicinal Plants Research 2011; Vol. 5(28), pp. 6435-6438.

[2] Stafford GI, Pedersen ME, van Staden J, Jäger AK. Review on plants with CNS-effects used in traditional South African medicine against mental diseases. J Ethnopharmacol. 2008; 119: 513-37.

[3] Argheore, E. M., Makka H. P. S. Beckerk, (1998) Feed value of some browse plants from central zone of Delta State of Nigeria. Trop. Sci. 38: 97 - 104.

[4] Rao, B. K. and C. H. Rao (2001) Hypoglycemic and antihyperglycemic activity of syzygium alternifolium (wt.) walp seed extracts in normal and diabetic rats. Phytomedicine, 8: 88-93.

[5] Joy, P. P., Thomas, J., Matthew, S. (1998) Medicinal Plants Kerala Agricultural Univ., Kerala, India. Pp $3-8$.

[6] Rates, S. M (2001) Plant as source of drug. Toxicon - 39(5), $603-613$.

[7] Tiwari, A. K., Rao, J. M. (2002) Diabetes Mellitus and multiple therapeutic approaches of phytochemicals: present status and future prospects. Current Science, 83(1), 30 - 37.

[8] Biodun Falodun, available at http://imoonline.com.ng/dir/index.php?option=com_content\& view $=$ article $\& \mathrm{id}=3386$ :the-medicinal-benefits-of-vernoniaamygdalina\&catid $=63$ :facts\&Itemid $=77$ Retrieved September 20th 2015.

[9] Ifeoma I. Ijeh and Chukwunonso E. C. C. Ejike Current perspectives on the medicinal potentials of Vernonia amygdalina Del. Journal of Medicinal Plants Research, Vol. 5(7), pp. 1051-1061, 2011.

[10] http://www.eduresourceworld.com/2013/10/medicinalimportance-of-bitter-leaf.html Retrieved September 20th 2015.

[11] Izevbigie, E. A., Bryant J. L., Walker A. A novel naturally inhibitor of extracellular signal - regulated kinases and human breast cancer cell growth. Exptal. Biol. Med 229(2): $163-169,2009$.
[12] Dallas John. Royal College of Physicians of Edinburgh. Diabetes, Doctor and Dogs: An exhibition on diabetes and endocrinology. 10: 220-23, 2011.

[13] Dwivedi, Girish \& Dwivedi Shridhar History of medicine: Sushruta - the Clinician -Teacher par Excellence. National Informatic Centre, pp. 200-204, 2007.

[14] Ekam V. S., 1Ebong P. E., 2Johnson J. T., 2Dasofunjo, K. 1Effect of Activity Directed Fractions of Vernonia amygdalina on Total Body Weight and Blood Glucose Levels of Diabetic Wistar Albino Rats International Journal of Science and Technology, Volume 2 No. 1, 153-157, 2013.

[15] B. W. Smith and L. A. Adams, "Nonalcoholic fatty liver disease and diabetes mellitus: pathogenesis and treatment," Nature Reviews Endocrinology, vol. 7, no. 8, pp. 456-465, 2011.

[16] H. Ahmadieh and S. T. Azar, "Liver disease and diabetes: association, pathophysiology, and management," Diabetes Research and Clinical Practice, vol. 104, no. 1, pp. 53-62, 2014.

[17] Amanda Natália Lucchesi, Lucas Langoni Cassettari, and César Tadeu Spadella Alloxan-Induced Diabetes Causes Morphological and Ultrastructural Changes in Rat Liver that Resemble the Natural History of Chronic Fatty Liver Disease in Humans Journal of Diabetes Research Volume 2015 (2015), Article ID 494578, 11 pages http://dx.doi.org/10.1155/2015/494578.

[18] V. G. Kozyritskij and A. G. Minchenko, "Ultrastructural alterations in rat hepatocytes under diabetes and insulin administration," Tsitologiya i Genetika, vol. 12, no. 5, pp. 397-401, 1978.

[19] K. Welt, J. Weiss, R. Martin et al., "Ultrastructural, immunohistochemical and biochemical investigations of the rat liver exposed to experimental diabetes and acute hypoxia with and without application of Ginkgo extract," Experimental and Toxicologic Pathology, vol. 55, no. 5, pp. 331-345, 2004.

[20] R. N. Remedio, A. Castellar, R. A. Barbosa, R. J. Gomes, and F. H. Caetano, "Morphology and protein content of hepatocytes in type I diabetic rats submitted to physical exercises," Micron, vol. 42, no. 5, pp. 484-491, 2011.

[21] MS Mir, MM Darzi, HM Khan, SA Kamil, AH Sofi, SA Wani Pathomorphological effects of Alloxan induced acute hypoglycaemia in rabbits Alexandria Journal of Medicine, Vol 49, No 4; 343-35, 2013.

[22] P. Evelson, C. Susemihl, I. Villarreal et al., "Hepatic morphological changes and oxidative stress in chronic streptozotocin-diabetic rats," Annals of Hepatology, vol. 4, no. 2, pp. 115-120, 2005.

[23] N. C. Leite, C. A. Villela-Nogueira, V. L. N. Pannain et al., "Histopathological stages of nonalcoholic fatty liver disease in type 2 diabetes: prevalences and correlated factors," Liver International, vol. 31, no. 5, pp. 700-706, 2011.

[24] S. E. Regnell and A. Lernmark, "Hepatic steatosis in type 1 diabetes," Review of Diabetic Studies, vol. 84, no. 4, pp. 454 467, 2011.

[25] J. P. Verderese and Z. Younossi, "Interaction of Type 2 diabetes and nonalcoholic fatty liver disease," Expert Review of Gastroenterology and Hepatology, vol. 7, no. 5, pp. 405407, 2013. 
[26] O. O. Azu, I. A. Edagha, A. I. Peter, I. Umoh and U. Abia. Extracts of Gongronema latifolium and Vernonia amygdalina improve glycaemia and histomorphology of testes of diabetic Wistar rats African Journal of Pharmacy and Pharmacology, vol 8 (43) 1093 - 1102, 2014.

[27] http://aloksinghpatel.blogspot.com/2012/12/hepatoprotectiveactivity.html Retrieved September 20th 2015.

[28] Dehmlow, Carola; Erhard, Jochen; De Groot, Herbert. Hepatology Inhibition of Kupffer cell functions as an explanation for the hepatoprotective properties of silibinin. 23 (4), 749-54. 1996.

[29] Jia X.-Y., Zhang Q.-A., Zhang Z.-Q., Wang Y., Yuan J.-F., Wang H.-Y., Zhao D."Hepatoprotective effects of almond oil against carbon tetrachloride induced liver injury in rats" Food Chemistry 2011 125: 2 (673-678).

[30] P.A. Akah, J.A Alemji, O.A Salawu, T.C. Okoye and N.V. OffiahEffects of Vernonia amygdalina on Biochemical and Hematological Parameters in Diabetic Rats Asian Journal of Medical Sciences, 1(3): 108-113. 2009.

[31] P. C. Ekeocha1, T.R. Fasola1, A. H. Ekeocha The effect of vernonia amygdalina on alloxan induced diabetic albino rats African Journal of Food Science and Technology Vol. 3(3) pp. 73-77. 2012.

[32] http://www.mayoclinic.org/diseases-conditions/diabetes/indepth/diabetes-treatment/art-20044084. Retrieved September 20th 2015. 